\title{
PENGAMATAN TERJADINYA KERAK CUCO3 PADA KETEL UAP
}

\author{
Adi Noviyanto ${ }^{1}$
}

\begin{abstract}
ABSTRAK
Kerak tembaga karbonat $\left(\mathrm{CuCO}_{3}\right)$ yang mengendap pada dinding pipa diselidiki dalam penelitian ini. Kerak tembaga karbonat adalah kerak yang sering terbentuk pada pipa boiler. Dalam eksperimental, larutan pembentuk kerak disiapkan dengan mencampurkan larutan equimolar $\mathrm{CuCl}_{2}$ dan $\mathrm{Na}_{2} \mathrm{CO}_{3}$. Tujuan dari penelitian ini adalah untuk membandingkan hasil penelitian tentang pembentukan kerak $\mathrm{CuCO}_{3}$ pada pipa boiler kerak $\mathrm{CuCO}_{3}$ dan pada pipa simulasi dengan suhu $300-400^{\circ} \mathrm{C}$. Kerak yang terbentuk kemudian dievaluasi menggunakan analisis karakteristik kerak dan SEM/EDX. Hasil penelitian menunjukkan bahwa kerak memiliki pelat seperti morfologi dan kerak fase kristal yang ditemukan sebagian besar malasite. Berdasarkan hasil ini, kerak $\mathrm{CuCO}_{3}$ di Boiler memiliki kondisi panas yang sangat tinggi dan waktu panas yang lama membuat kerak $\mathrm{CuCO}_{3}$ berwarna hitam. Warna dan tekstur kerak $\mathrm{CuCO}_{3}$ pada pipa menunjukkan warna yang lebih cerah. Kerak yang terbentuk kemudian dievaluasi menggunakan analisis SEM / EDX. Perbandingan analisis antara hasil analisis kerak $\mathrm{CuCO}_{3}$ pada pipa boiler dan pipa simulator menunjukkan hasil yang berbeda. Hasil analisis SEM menunjukkan bahwa kristal yang dilakukan melalui eksperimen diambil dari boiler dan pipa. Perbedaan morfologi dan komposisi antara sampel kedua adalah karena boiler lebih panas daripada di pipa sehingga morfologi kristal $\mathrm{CuCO}_{3}$ dalam boiler lebih rapat dibandingkan di pipa.
\end{abstract}

Kata kunci: Kerak, Ketel Uap, $\mathrm{CuCO} 3$

\section{PENDAHULUAN}

Kerak adalah tumpukan keras dari bahan anorganik terutama pada permukaan perpindahan panas yang disebabkan oleh pengendapan partikel mineral dalam air. Seperti air menguap dalam menara pendingin, uap yang murni hilang dan konsentrasi padatan terlarut dalam air yang tersisa. Jika konsentrasi siklus ini dibiarkan berlanjut, berbagai kelarutan padat akhirnya akan terlampaui. Padatan kemudian akan menetap di dalam pipa atau pada permukaan pertukaran panas, di mana ia sering membeku menjadi kerak (Bhatia, 2003).

Potensi kerak yang disebabkan oleh garam $\mathrm{CuCO}_{3}$ (kupri karbonat) dimiliki hampir semua jenis sumber air di dunia seperti air tanah, air payau, air laut serta air limbah. Kupri karbonat membentuk padatan atau deposit yang sangat kuat menempel pada permukaan material. Sejauh ini $\mathrm{CuCO}_{3}$ merupakan penyebab kerak pada beberapa sistem seperti instalasi cooling water (Tzotzi dkk, 2007). Penyebab terjadi kerak di dalam pipa akan mengurangi diameter serta menghambat aliran fluida pada sistem pipa tersebut, sehingga menimbulkan

\footnotetext{
${ }^{1}$ Jurusan Teknik Mesin, Fakultas Teknik,Universitas Muhammadyah Semarang
} 
masalah terhambatnya aliran fluida. Terganggunya aliran fluida tersebut menyebabkan tekanan semakin tinggi, sehingga pipa mengalami kerusakan (Asnawati, 2001). Pembentukan kerak dapat dicegah dengan cara pelunakan dan pembebasan mineral air, akan tetapi penggunaan air bebas mineral dalam industri-industri besar membutuhkan biaya yang lebih tinggi (Sousa dan Bertran, 2014).

Peningkatan laju aliran akan memperpendek periode induksi karena meningkatkan frekuensi pertumbuhan molekul dalam larutan. Tingkat pertumbuhan kristal ditentukan oleh kemampuan difusi zat terlarut kepermukaan kristal dan kemapuan pengendapan zat terlarut di permukaan. Kekuatan yang memudahkan difusi zat terlarut adalah perbedaan konsentrasi zat terlarut antara permukaan kristal dan larutan. Faktor yang perlu diperhatikan dalam laju difusi zat terlarut adalah laju alir. Laju aliran air dan pH-perlakuan pada perangkat magnet memiliki dampak penting pada jenis nukleasi dan jumlah kupri karbonat yang diendapkan pada akhir uji pengerakan. Laju aliran dan pH-perlakuan sekaligus laju pengendapan yang semakin tinggi, memperbanyak nukleasi yang terjadi dalam larutan (Alimi dkk, 2007).

Hisyam (2013) menyatakan bahwa dengan meningkatnya laju aliran menyebabkan waktu induksi lebih cepat. Hal tersebut karena selain membawa komponen kerak lebih banyak dalam fluida, laju alir yang tinggi menyebabkan ion bergerak lebih cepat yang berdampak semakin cepat pula reaksi yang terjadi antar ion.

Oleh karena itu, pada penelitian ini mempelajari tentang analisa pembentukan kerak $\mathrm{CuCO}_{3}$ pada boiler dan pipa di PG Trankil, sehingga pertumbuhan kerak kupri karbonat yang terbentuk di dalam pipa-pipa industri dapat diketahui. Penelitian ini juga mempelajari perubahan fasa kristal dan pertumbuhan massa kerak.

\section{METODOLOGI}

\section{Alat dan Bahan}

Bahan yang digunakan untuk persiapan larutan pembentuk kristal adalah $\mathrm{CuCl}_{2}$ dan $\mathrm{Na}_{2} \mathrm{CO}_{3}$ dengan kadar analitik. Larutan dibuat dengan konsentrasi $3000 \mathrm{ppm} \mathrm{Cu}^{2+}$. kerak pembentukan $\mathrm{CuCO} 3$ ditanam menggunakan peralatan skala pilot yang ditunjukkan pada Gambar 1.

\section{Metode Eksperimen Pembentukan Kerak CuCO3}

Percobaan pembentukan kerak $\mathrm{CuCO} 3$ dilakukan dengan menyiapkan, lima liter $\mathrm{CuCl}_{2}$ dan $\mathrm{Na}_{2} \mathrm{CO}_{3}$ disiapkan dalam gelas kimia. Percobaan ini dilakukan dalam metode yang sama yang diusulkan oleh Muryanto et al (2014), dengan melarutkan serbuk $\mathrm{CuCl}_{2}$ dan $\mathrm{Na}_{2} \mathrm{CO}_{3}$ 
dengan konsentrasi $\mathrm{Cu}^{2+} 3000$ ppm. Larutan pada konsentrasi yang telah ditentukan ditempatkan secara terpisah di kedua kapal dan diseimbangkan sampai suhu yang ditentukan tercapai kemudian diaduk pada 200 rpm sampai tercampur dengan baik.

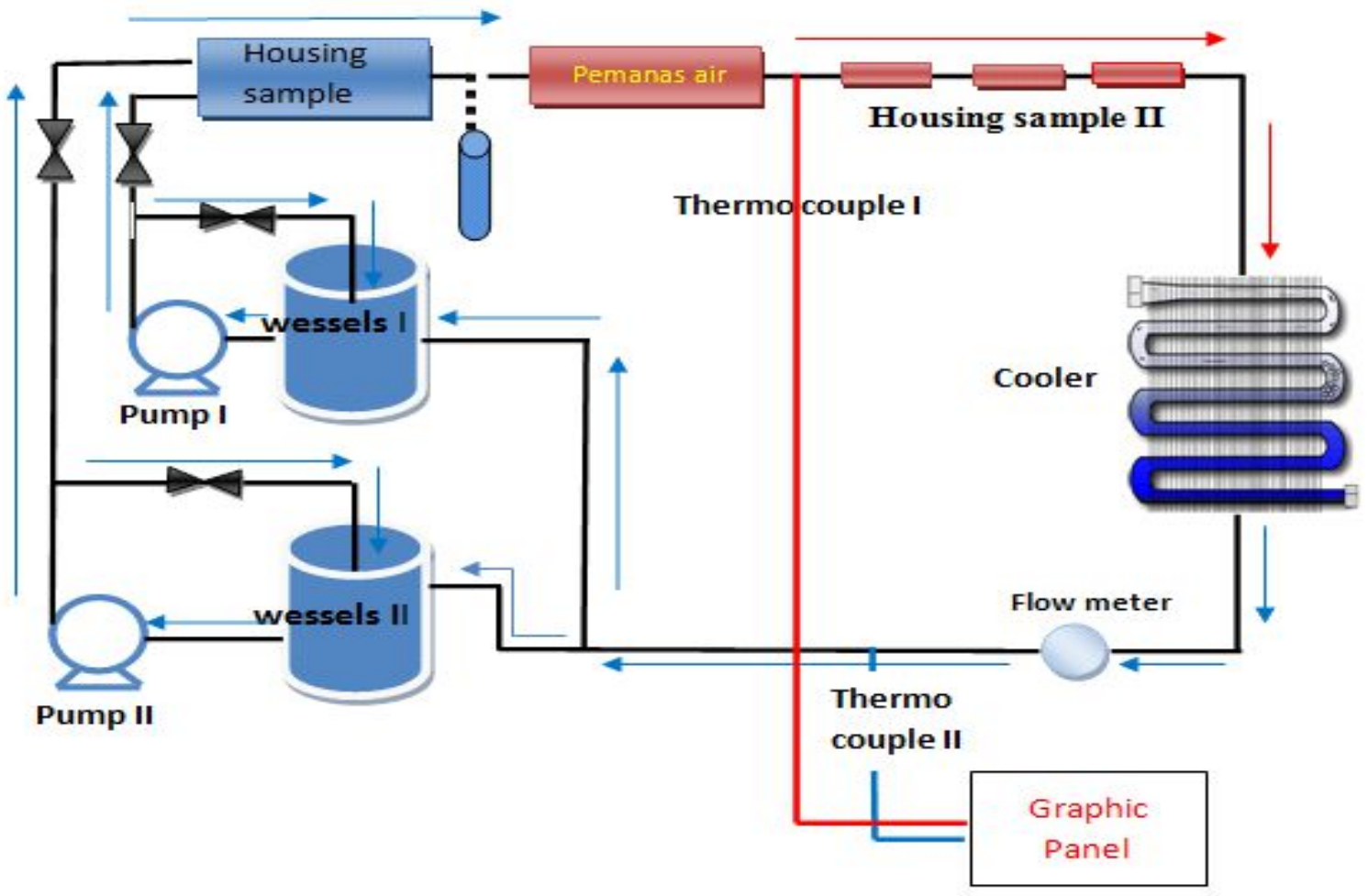

Gambar 1 Experimental Setup Pembentukan Kerak $\mathrm{CuCO}_{3}$

\section{Analisa Karakterisasi}

Karakterisasi kristal kerak dilakukan dengan pemindaian mikroskop elektron (SEManalisis) untuk uji morfologi, dilengkapi dengan EDX untuk analisis unsur kimia dan XRD untuk analisis identifikasi fase. Pengumpulan data XRPD untuk identifikasi fase dilakukan dengan menggunakan radiasi monokrom $\mathrm{Cu}-\mathrm{K}$ dalam geometri parafokus konvensional Bragg-Brentano (BB) (D5005 SHIMATZU). Parameter pemindaian (5-85 O2, 0,020 langkah, 15 s / langkah) direkam. Program pencarian-pencocokan berbasis PC, Software MATCH digunakan untuk mengidentifikasi kemungkinan fase kristal endapan.

\section{HASIL DAN PEMBAHASAN}

\section{Analisa Perbandingan Karakteristik Kerak $\mathrm{CuCO}_{3}$ pada Boiler and Pipa}

Penelitian pada kerak $\mathrm{CuCO}_{3}$ dilakukan untuk menentukan perbandingan karakteristik kerak $\mathrm{CuCO}_{3}$ terhadap Bolier pada suhu $400^{\circ} \mathrm{C}-450^{\circ} \mathrm{C}$ dengan panjang pipa $12 \mathrm{~m}$ yang 
digunakan untuk 2904 jam dan Pipa. Perbandingan karakteristik kerak $\mathrm{CuCO}_{3}$ dapat ditunjukkan pada Tabel 1.

Tabel 1. Perbandingan karakteristik kerak $\mathrm{CuCO}_{3}$

\begin{tabular}{|c|c|c|}
\hline Paramater & Pada boiler & Pada Pipa \\
\hline Warna & Hitam & Abu-Abu \\
\hline Bau & Khas & Khas \\
\hline Textur & Kasar & Halus \\
\hline
\end{tabular}

Pada Tabel 1. menunjukkan kerak $\mathrm{CuCO}_{3}$ di Boiler memiliki warna hitam dan tekstur kasar. Kerak $\mathrm{CuCO}_{3}$ dalam pipa memiliki warna abu-abu dan tekstur lebih halus. Berdasarkan hasil ini ditunjukkan bahwa kerak $\mathrm{CuCO}_{3}$ dalam boiler memiliki kondisi suhu yang sangat tinggi dan waktu panas yang lama, sehingga membuat warna kerak $\mathrm{CuCO}_{3}$ terbentuk hitam. Warna dan tekstur kerak $\mathrm{CuCO}_{3}$ pada pipa menunjukkan warna yang lebih cerah. Hasil ini terjadi karena pipa memiliki kondisi suhu yang lebih rendah dan waktu pemanasan yang lebih singkat. Pengambilan sampel kerak $\mathrm{CuCO} 3$ di Trankil PG ditunjukkan pada Gambar 2.

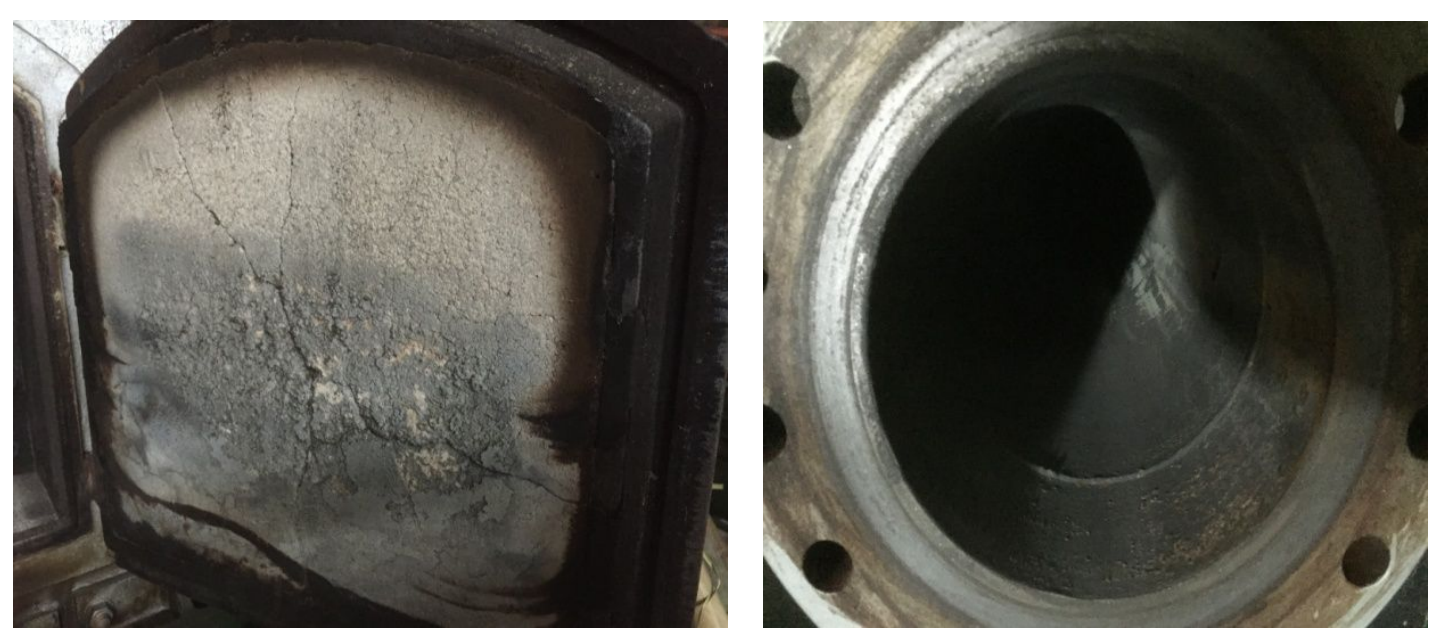

Gambar 2. Scale in Boiles and Pipe

\section{Analisis Perbandingan Morfologi Kerak $\mathrm{CuCO}_{3}$}

Pengujian SEM dan pengujian microanalyser dapat dilakukan pada instrumen dengan menggunakan perangkat SEM / EDX. Pengujian SEM dilakukan untuk menilai morfologi kristal sedangkan uji analisis mikro bertujuan untuk menentukan komposisi Kupri karbonat. 
Studi morfologi adalah studi yang meliputi kekasaran kristal, ukuran kristal, bentuk kristal, proses pengintaian dan fenomena pembentukan kristal.

\section{Kerak $\mathrm{CuCO}_{3}$ Pada Boiler}

Setelah dilakukan pengamatan pada hasil SEM yang tercantum pada Gambar 3 dan 4 dengan berbagai perbesaran. Proses pembentukan kristal yang dilakukan melalui eksperimen diambil dari boiler dan pipa. Perbedaan morfologis antara dua sampel adalah karena kondisi di boiler menjadi lebih panas daripada di pipa sehingga morfologi kristal $\mathrm{CuCO}_{3}$ di boiler lebih padat daripada di pipa.

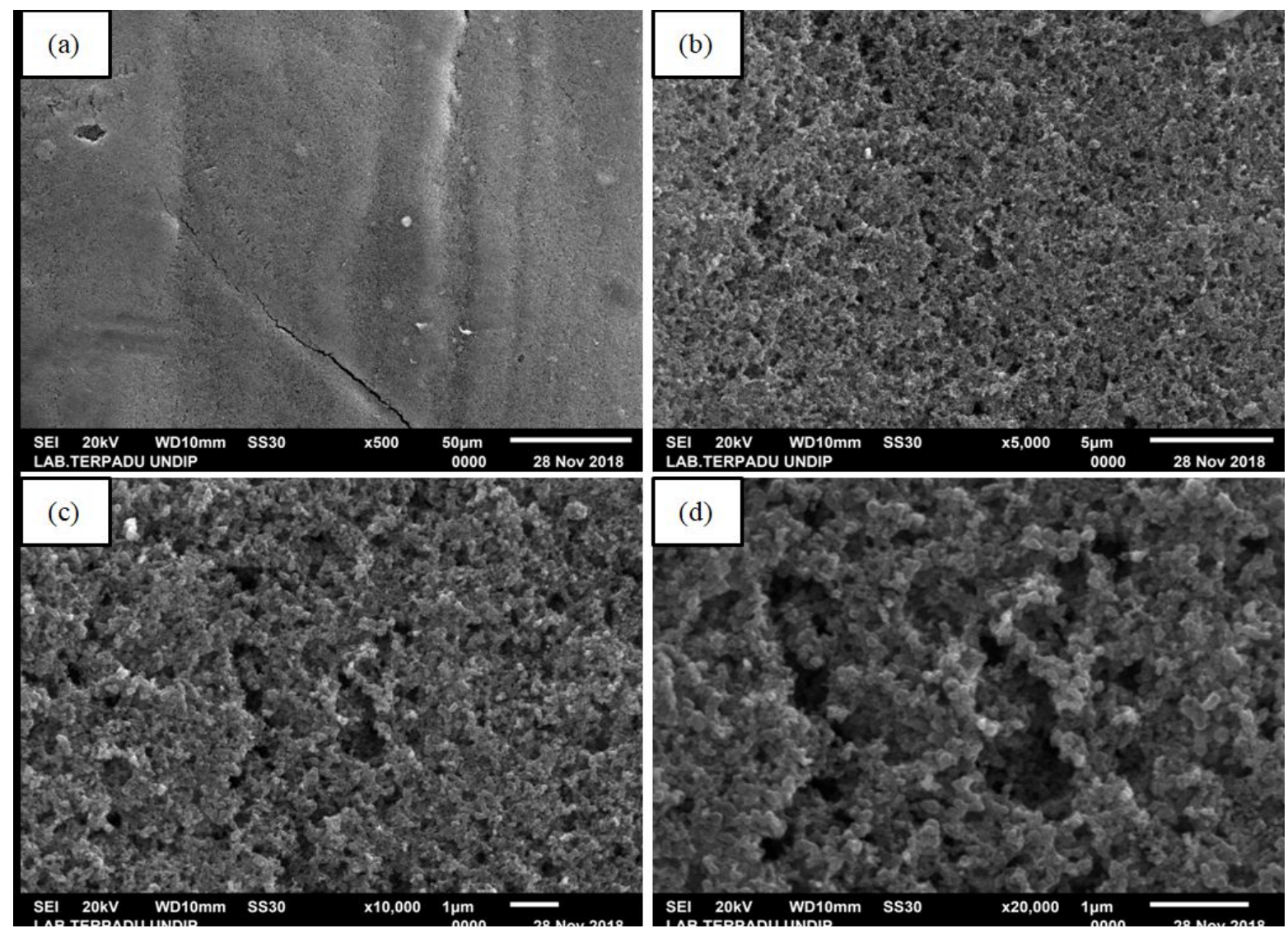

Gambar 3. Morfologi kerak $\mathrm{CuCO}_{3}$ pada Boiler

(a) $500 \mathrm{X}$, (b) $5000 \mathrm{X}$ (c) $10000 \mathrm{X}$, and (d) $20000 \mathrm{X}$

\section{Kerak $\mathrm{CuCO}_{3}$ dalam Pipa}

Dari dua hasil uji SEM itu menunjukkan bahwa suhu yang lebih besar dapat meningkatkan pembentukan fase kristal yang merupakan jenis fase hardscale. Jika kristal ini terbentuk dan mengendap di dalam pipa, ia akan menghasilkan skala yang sulit dibersihkan dari sistem perpipaan (Holysz dkk, 2007). 

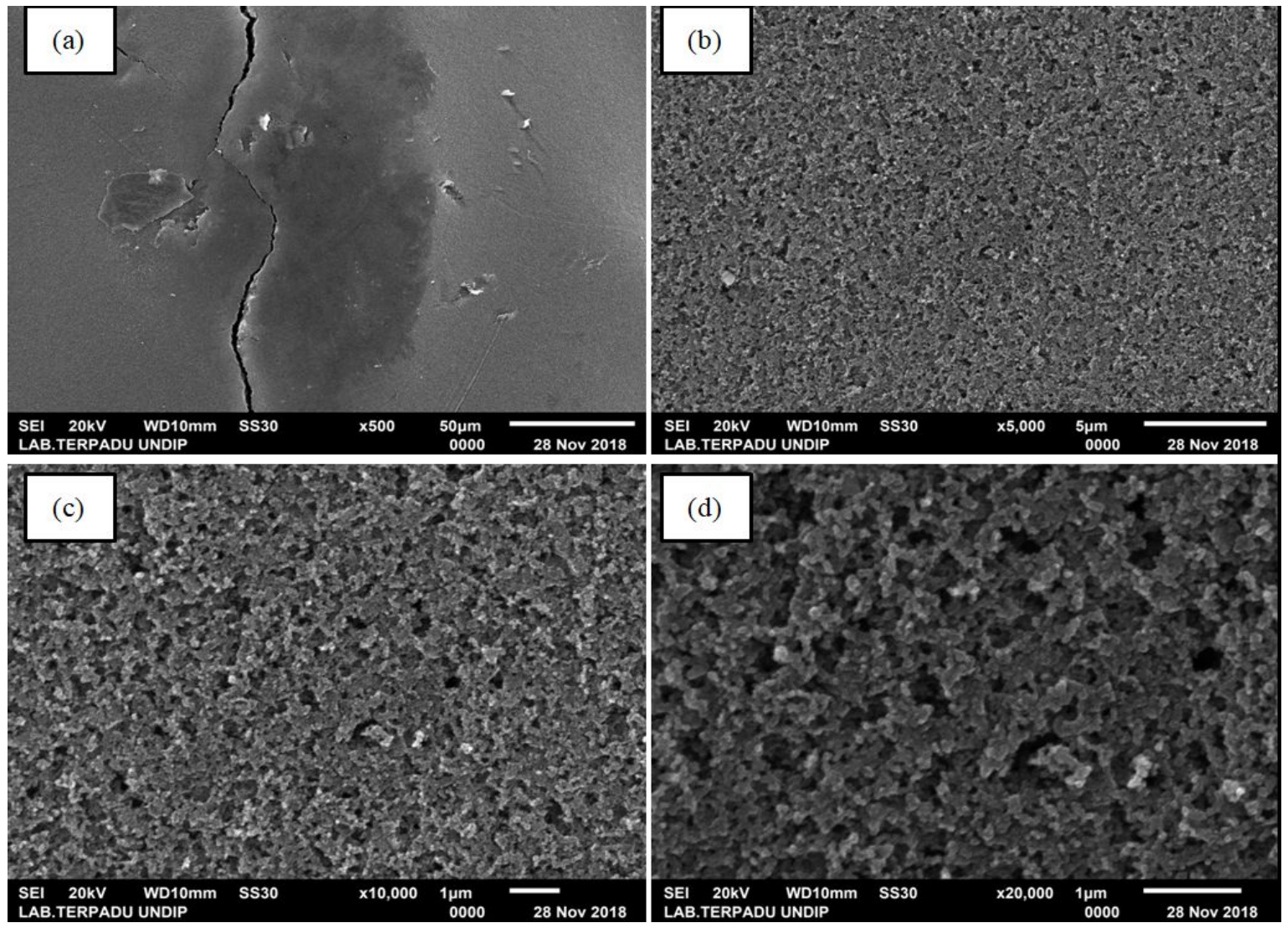

Gambar 4. Morfologi kerak CuCO3 dalam Pipa

(a) 500X, (b) 5000X (c) 10000X, and (d) 20000X

\section{Analisis Perbandingan Komposisi Kerak $\mathrm{CuCO}_{3}$}

Pada prinsipnya mikroskop elektron dapat mengamati morfologi, struktur mikro, komposisi, dan distribusi elemen. Untuk menentukan komposisi unsur secara kualitatif dan kuantitatif, satu perangkat EDS (Energy Dispersive X-ray Spectrometer).

\section{Kerak $\mathrm{CuCO}_{3}$ Pada Boiler}

Menurut perhitungan teoritis, persentase berat konten $\mathrm{Cu}$ dalam $\mathrm{CuCO} 3$ harus 63,5 / $100 \times 100 \%=63,5 \%$ sedangkan hasil analisis mikro dengan $\mathrm{Cu}=1,05 \%$ sehingga memiliki perbedaan $62,45 \%$. Untuk kadar karbon (C) harus $12 / 100 \times 100 \%=12 \%$ sedangkan hasil analisis mikro diperoleh 70\% sehingga memiliki perbedaan 58\%. Untuk kadar oksigen harus $16 / 100 \times 100 \%=16 \%$ sedangkan hasil analisis mikro adalah $28,95 \%$ sehingga memiliki perbedaan $12,95 \%$. 


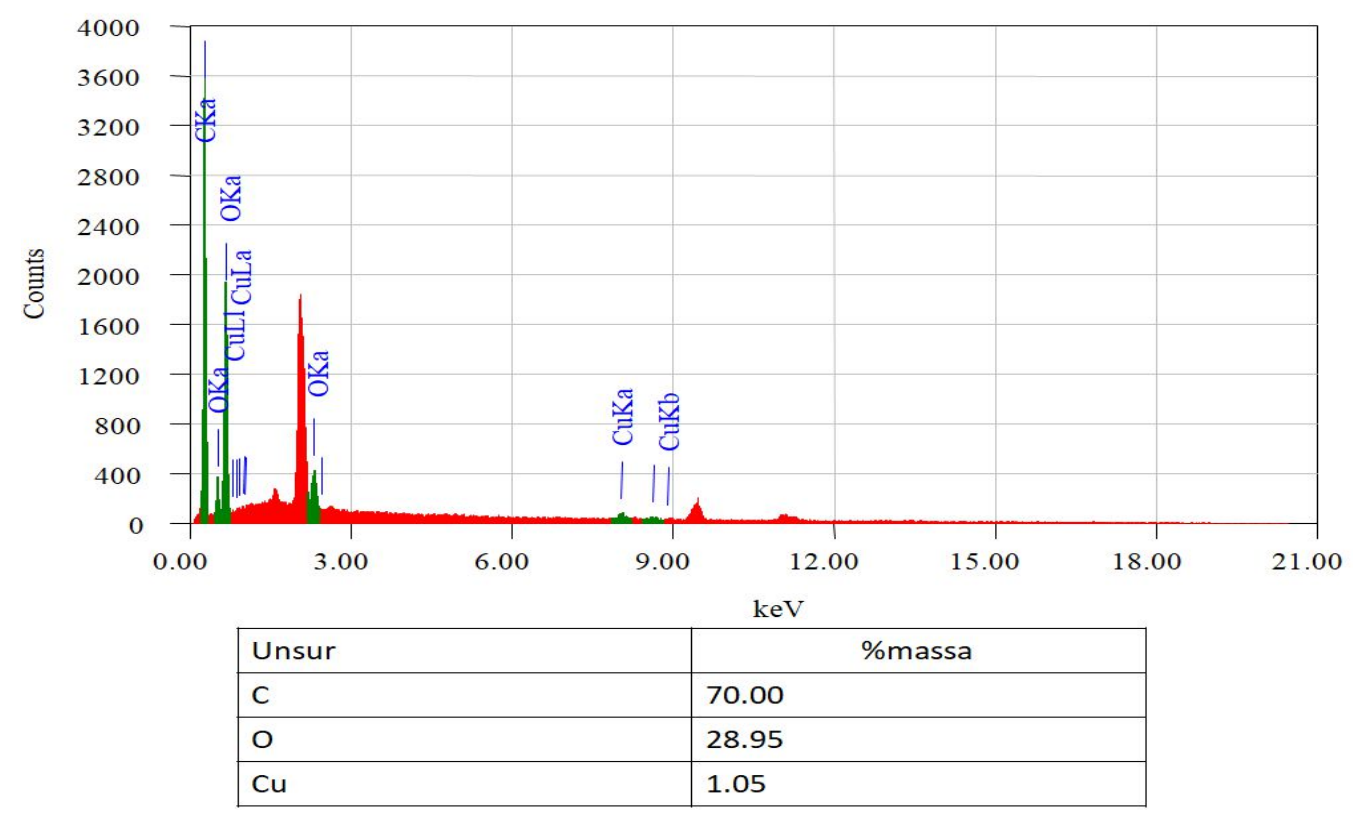

Gambar 5. Komposisi kerak $\mathrm{CuCO}_{3}$ pada boiler

\section{Kerak $\mathrm{CuCO}_{3}$ Pada Pipa}

Menurut perhitungan teoritis, persentase berat konten $\mathrm{Cu}$ dalam $\mathrm{CuCO} 3$ harus 63,5 / $100 \times 100 \%=63,5 \%$ sedangkan hasil analisis mikro dengan konten $\mathrm{Cu}=0,21 \%$ sehingga memiliki perbedaan 63,29\%. Untuk kandungan karbon (C) harus 12/100 x 100\% $=12 \%$ sedangkan hasil analisis mikro diperoleh $77,21 \%$ sehingga memiliki perbedaan $65,12 \%$. Untuk kadar oksigen harus 16/100 x 100\% = 16\% sedangkan hasil analisis mikro membahas $22,58 \%$ sehingga memiliki perbedaan $6,58 \%$.

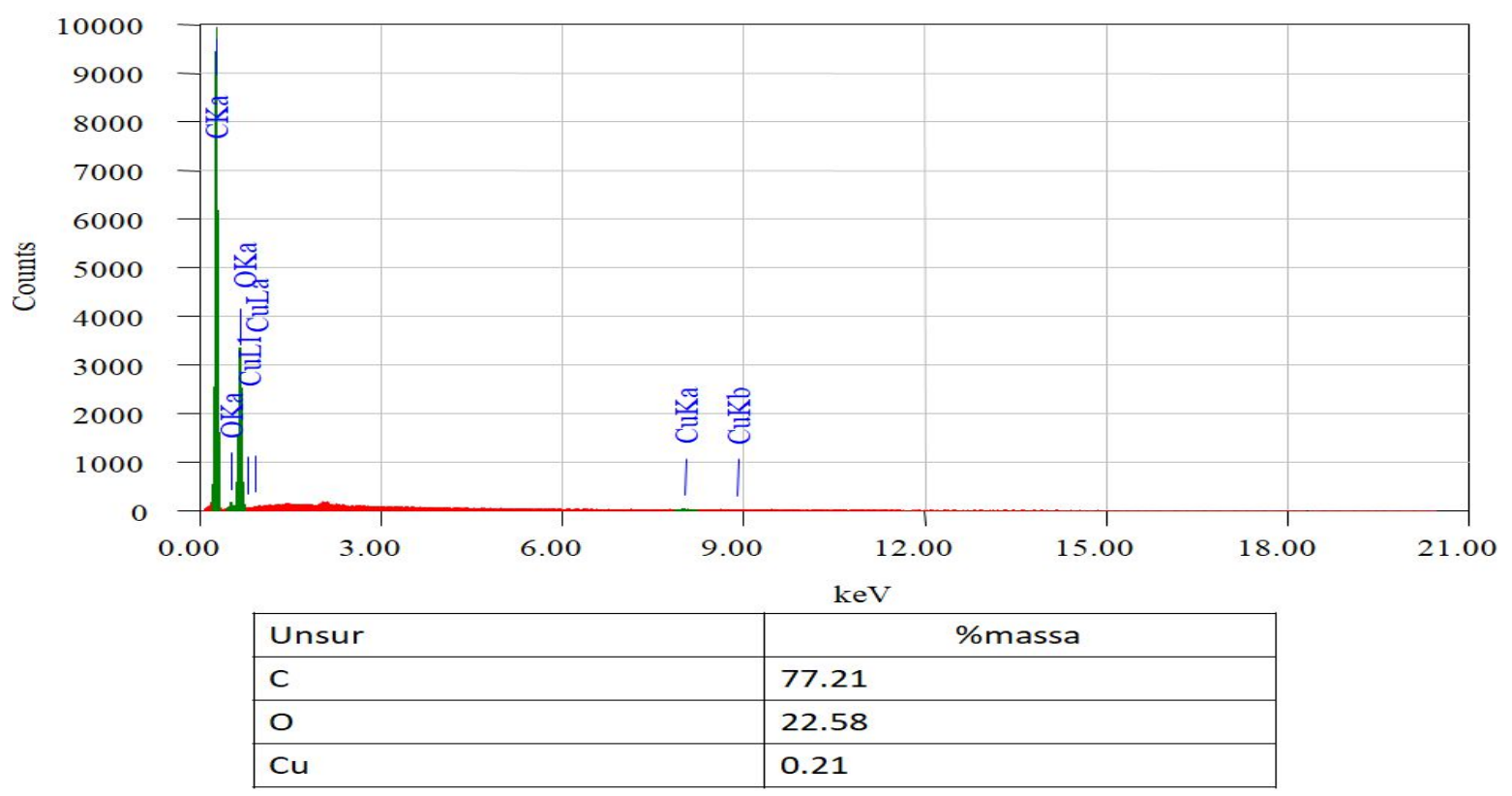

Gambar 6. Komposisi kerak CuCO3 pada Pipa 


\section{KESIMPULAN}

Berdasarkan hasil penelitian dan pembahasan yang telah diuraikan dapat disimpulkan bahwa:

1. Berdasarkan hasil tersebut menunjukan bahwa kerak $\mathrm{CuCO} 3$ pada Boiler memiliki kondisi suhu yang sangat tinggi dan waktu panas yang lama sehingga membuat warna kerak $\mathrm{CuCO} 3$ yang terbentuk menjadi hitam. Warna dan tekstur kerak $\mathrm{CuCO} 3$ pada pipa menunjukan warna yang lebih terang. Hasil ini terjadi karena pada pipa kondisi suhu lebih rendah dan waktu pemanasan yang lebih singkat.

2. Hasil analisa SEM menunjukan pembentukan kristal yang dilakukan melalui percobaan diambil dari boiler dan pipa. Perbedaan morfologi antara kedua sampel tersebut disebabkan karena kondisi di boiler lebih panas dibandingkan di dalam pipa sehingga morfologi kristal $\mathrm{CuCO} 3$ pada boiler lebih rapat dibandingkan di dalam pipa.

3. Hasil analisa EDX menunjukan persentase unsur $\mathrm{Cu}$ lebih benyak terdapat pada pipa boiler sedangkan pada pipa simulasi menghasilkan persentase $\mathrm{Cu}$ yang lebih sedikit.

\section{DAFTAR PUSTAKA}

Alimi, F., Tlili, M., Amor, M.B., Gabrielli, C., Maurin, G. (2007), Influence of magnetic field on calcium carbonate precipitation, Desalination, 206, 163-168.

Asnawati., (2001). Pengaruh temperatur terhadap reaksi fosfonat dalam inhibitor kerak pada sumur minyak. Jurnal Ilmu Dasar, Vol.2. No.1, Hal.20-26.

Bhatia, A. (2003), "cooling water problems and solutions", Continuing Education and Development, Inc. 9 Greyridge Farm Court Stony Point, NY 10980. Course No : 05-009.

Muryanto, S., Bayuseno, A. P., Ma'mun, H., Usamah, M. (2014). Calcium carbonate scale formation in pipes: effect of flow rates, temperature, and malic acid as additives on the mass and morphology of the scale Procedia Chemistry, 9, 69-76

Reiterer, W. Johannes, H. Gamsjäger (1981): "Semimicro Determination of Solubility Constants: Copper (II) Carbonate and Iron (II) Carbonate". Mikrochim. Acta, volume 1981, page 63. doi:10.1007/BF01198705

Reiterer (1980): "Löslichkeitskonstanten und Freie Bildungsenthalpien neutraler Übergangsmetallcarbonate". Thesis, Montanuniversität Leoben.

Rolf Grauer (1999) "Solubility Products of M(II) Carbonates". Technical Report NTB99-03, NAGRA - National Cooperative for the Disposal of Radioactive Waste; pages 8,14 , and 17 . Translated by $\mathrm{U}$. Berner. 
Sousa, M.F., Bertran, C.A. (2014). New methodology based on static light scattering measurements for evaluation of inhibitors for in bulk crystallization Journal of Colloid and Interface Science. Pp.57-64.

Tzotzi, C., Pahiadaki, T., Yiantsios, S.G., Karabelas, A.J., Andritsos, N. (2007). A study of $\mathrm{CaCO}_{3}$ skala formation and inhibition in $\mathrm{RO}$ and $\mathrm{NF}$ membrane processes. Journal of Membrane Science,296(1), pp.171-184.

\section{PENULIS:}

\section{ADI NOVIYANTO}

Jurusan Teknik Mesin, Fakultas Teknik,Universitas Muhammadyah Semarang

Corresponding author. Tel. $+62-82236123443$

E-mail address: adinoviyanto88@gmail.com 